Review

\title{
Renal Dopamine Receptors, Oxidative Stress, and Hypertension
}

\author{
Santiago Cuevas *, Van Anthony Villar, Pedro A. Jose and Ines Armando \\ Department of Medicine, Division of Nephrology, University of Maryland School of Medicine, \\ 20 Penn St., HSFII, Suite S003, Baltimore, MD 21201-1599, USA; \\ E-Mails: vvillar@medicine.umaryland.edu (V.A.V.); pjose@medicine.umaryland.edu (P.A.J.); \\ iarmando@medicine.umaryland.edu (I.A.)
}

* Author to whom correspondence should be addressed; E-Mail: scuevas@medicine.umaryland.edu; Tel.: +1-410-706-6017; Fax: +1-410-706-6034.

Received: 1 July 2013; in revised form: 9 August 2013 / Accepted: 12 August 2013 /

Published: 27 August 2013

\begin{abstract}
Dopamine, which is synthesized in the kidney, independent of renal nerves, plays an important role in the regulation of fluid and electrolyte balance and systemic blood pressure. Lack of any of the five dopamine receptor subtypes (D1R, D2R, D3R, $\mathrm{D} 4 \mathrm{R}$, and D5R) results in hypertension. D1R, D2R, and D5R have been reported to be important in the maintenance of a normal redox balance. In the kidney, the antioxidant effects of these receptors are caused by direct and indirect inhibition of pro-oxidant enzymes, specifically, nicotinamide adenine dinucleotide phosphate, reduced form (NADPH) oxidase, and stimulation of anti-oxidant enzymes, which can also indirectly inhibit NADPH oxidase activity. Thus, stimulation of the D2R increases the expression of endogenous anti-oxidants, such as Parkinson protein 7 (PARK7 or DJ-1), paraoxonase 2 (PON2), and heme oxygenase 2 (HO-2), all of which can inhibit NADPH oxidase activity. The D5R decreases NADPH oxidase activity, via the inhibition of phospholipase D2, and increases the expression of HO-1, another antioxidant. D1R inhibits NADPH oxidase activity via protein kinase $A$ and protein kinase $C$ cross-talk. In this review, we provide an overview of the protective roles of a specific dopamine receptor subtype on renal oxidative stress, the different mechanisms involved in this effect, and the role of oxidative stress and impairment of dopamine receptor function in the hypertension that arises from the genetic ablation of a specific dopamine receptor gene in mice.
\end{abstract}

Keywords: dopamine receptors; oxidative stress; kidney; hypertension 


\section{Introduction}

The redox state of cells can be defined as the steady state condition whereby the generation of free radical/highly reactive species is balanced by antioxidant mechanisms. Reactive oxygen species (ROS) normally act as cellular messengers. Enzymes that produce ROS are present in subcellular compartments, including lipid rafts, such that ROS levels can increase to a critical level for signal transduction and then be destroyed in a timely manner [1,2]. ROS are also involved in the destruction of invading pathogens and low levels of ROS may increase life span (hormesis) [3]. However, increased oxidative stress and its failure to return to initially normal levels disrupt normal cellular signaling mechanisms [4-6]. The disturbance in the normal redox state of cells results in oxidative stress, a condition characterized by an overproduction of free radicals that are toxic to the cell.

Several families of enzymes and receptors are involved in the regulation of redox balance, including the nicotinamide adenine dinucleotide, reduced form (NADPH) oxidase, and the dopamine receptors. The Nox family of NADPH oxidases is comprised of enzymes that couple electrons from NADPH to molecular oxygen to generate superoxide. There are seven Nox homologs, four of which (Nox1, Nox2, Nox4, and Nox5) are found in the vasculature and the kidney where they constitute the major sources of ROS [7,8]. Increased Nox activity boosts the production of ROS that participate in the pathogenesis of several disorders, including hypertension [7-9]. For example, Nox1, Nox2, and Nox4 are increased in several tissues in rats with spontaneous hypertension or angiotensin II-induced hypertension [10-13]. However, the role of Nox4 in hypertension is not entirely clear because Nox4 knockout mice are normotensive [9]. The protein expression of the Nox5 gene, which is present in humans but not rodents, is greater in renal proximal tubular cells from hypertensive than normotensive humans, and may account for the increased oxidative stress in renal proximal tubule cells from hypertensive humans [14]. Several studies have shown that NADPH oxidase [15,16], by direct and indirect mechanisms, can be positively regulated by ROS, causing a positive "feedback loop" that may trigger the development of diseases such as hypertension. However, oxidative stress has yet to be established as a cause of human essential hypertension. Species specificity has to be kept in mind. For example, the role of lipid rafts in the production of ROS is species-specific; in renal proximal tubule cells, lipid rafts keep NADPH oxidase in the active state in rats but keep NADPH oxidase in the inactive state in humans $[17,18]$.

\subsection{Renal Dopaminergic System}

Dopamine is synthesized by the kidney, mainly by renal proximal tubule cells, independent of renal nerves. Unlike in neural tissue dopamine synthesized by renal tubules is not converted to norepinephrine. Renal dopamine is crucial in the maintenance of normal fluid, electrolyte balance, and redox balance and blood pressure [19]. The importance of renal endogenous dopamine in body homeostasis is demonstrated in genetically altered mice with decreased or increased renal dopamine production. The selective deletion in the mouse renal proximal tubule of aromatic amino acid decarboxylase (AADC), the enzyme responsible for the production of dopamine in the kidney, decreased intrarenal dopamine levels, and caused salt-sensitive hypertension [20]. Deletion of catechol-O-methyl transferase (COMT), which degrades dopamine to 3-methoxytyramine, is associated with increased dopamine levels. Transplanting the kidney from $\mathrm{COMT}^{-/}$mice into diabetic 
wild-type mice ameliorated the consequences of diabetes, decreasing albuminuria, glomerulopathy, inflammation, oxidative stress, and fibrosis, effects that were aggravated by the proximal tubular deletion of AADC [21].

Dopamine exerts its actions via two subfamilies of $\mathrm{G}$ protein-coupled receptors (GPCRs), namely, the D1-like dopamine receptors (D1R and D5R subtypes) and D2-like dopamine receptors (D2R, D3R, and D4R subtypes). All the dopamine receptor subtypes are differentially expressed along the nephron, from the proximal tubule to the collecting duct. The D1-like receptors couple to Gas and stimulate adenylyl cyclases, while the D2-like receptors couple to Gai and Go, inhibit adenylyl cyclases and calcium channels, and modulate potassium channels. Dopamine also stimulates renal prostaglandin synthesis via D2-like rather than D1-like receptors [19]. Both subfamilies of dopamine receptors link to MAPK activation, although through different pathways. Dopamine receptors may also exert their actions by inhibiting signaling pathways. Thus, the D2R can suppress Akt (protein kinase B) signaling [22]. The dopamine receptors interact among themselves, resulting in new signaling pathways that are probably cell specific. For example, in neurons, the interaction between D1R and D2R can lead to stimulation of phospholipase C [23]. However, D1R, independent of D2R, can stimulate phospholipase $C \beta 1$ in renal cortical cells [24] and phospholipase $C \gamma$ in fibroblasts [25].

\subsection{Reactive Oxygen Species}

ROS are important in the pathogenesis of hypertension and the increase in ROS production and blood pressure, caused by stimulation of the renin-angiotensin-aldosterone system, is well known. However, the negative regulators of ROS production are not well understood. Some downstream negative regulators of ROS, e.g., epoxyeicosatrienoic acids, are known but the negative regulators upstream to these pathways are relatively unknown. One such upstream negative regulator, under physiological conditions, may be the renal dopaminergic system [19]. Intrarenal dopamine counteracts the oxidative stress in deoxycorticosterone acetate/high salt-induced hypertension and angiotensin II-mediated renal injury [26]. Dopamine counteracts oxidative stress not only by inhibiting pro-oxidant enzymes, e.g., NADPH oxidase, but also by stimulating antioxidant enzymes, e.g., extracellular superoxide dismutase (SOD), heme-oxygenase (HO). However, dopamine, at high concentrations $(\geq 10 \mu \mathrm{M})$ [27,28], can lead to increased ROS production as a consequence of auto- or enzymatic oxidation $[29,30]$.

In this review, we provide an overview of the role of each of the dopamine receptor subtypes in the regulation of renal oxidative stress, the mechanisms involved in these effects, and the participation of oxidative stress in the hypertension that develops in dopamine receptor knockout mice.

\section{Renal Dopamine Receptor Regulation of Oxidative Stress}

\subsection{D1-Like Receptors}

\subsubsection{Renal Expression of D1-Like Dopamine Receptors}

The D1-like dopamine receptors, D1R and D5R, are expressed in the apical and basolateral membranes of the proximal tubule, medullary thick ascending limb of Henle, distal convoluted tubule, 
and cortical collecting duct [19,31-33]. They are not found in the glomerulus [19], although they are expressed in mouse glomerular podocytes in culture [34]. D1R, but not D5R, is expressed in the macula densa and juxtaglomerular cells in rats [35]. The expression of either D1R or D5R has not been reported in macula densa or juxtaglomerular cells in the human or mouse kidney [33]. Both D1R and D5R receptors are present in the small and large intrarenal arteries in rodents and humans [32,33,36,37].

Renal D1-like receptors are major physiological regulators of epithelial sodium transport and the lack of the expression or function of these receptors is associated with renal retention of sodium and increased blood pressure [19,38].

\subsubsection{D1-Like Receptors Negatively Regulate ROS Production}

As with high concentrations of dopamine, high concentrations of D1-like receptor agonist $(100 \mu \mathrm{M}$, SKF38393) [39] can also increase ROS production. However, low concentrations of D1-like receptor agonists decrease oxidative stress in many cells, including lymphocytes, and brain cortical, vascular smooth muscle, and renal proximal tubule cells [17-19,40-42], by decreasing the production of ROS [17-19,40-42] and reactive nitrogen [43]. Several signaling pathways are involved in the antioxidant effects of D1-like receptors. In retinal ganglion cells, D1-like receptor stimulation attenuated hydrogen peroxide-induced injury via the ERK and p38 pathways [44]. In vascular smooth muscle cells, D1-like receptor agonists inhibited platelet-derived growth factor-BB-mediated oxidative stress through activation of protein kinase A (PKA), and suppression of phospholipase D (PLD) and protein kinase $\mathrm{C}(\mathrm{PKC})$. The PKA inhibitor $\mathrm{H}-89$ reduced the antioxidant effect of dopamine in rat vascular smooth muscle cells, effects that were blocked by treatment with antisense oligonucleotides to either D1-like receptor subtype, indicating that in these cells the two D1-like receptor subtypes mediate the antioxidant effect of dopamine [41,45].

The antioxidant effects of D1-like receptors are eventually exerted by inhibiting the pro-oxidant enzyme, NADPH oxidase, and stimulating the anti-oxidant enzyme, heme oxygenase-1 (HO-1) [19]. The ability of D1-like receptors to stimulate antioxidant enzymes such as glutathione peroxidase, SOD-1, and glutamylcysteine transferase, involves Nrf-2 [46]. However, the pathways involved in these effects may be specific to D1R or D5R. Studies in HEK293 cells heterologously expressing either the human D1R or the human D5R have shown that the pathway involved in the inhibition of NADPH oxidase activity is D1-like receptor specific. Thus, the inhibition of NADPH oxidase by the D1R is mediated by stimulation of PKA and PKC cross-talk [47]. By contrast, the D5R decreases NADPH oxidase activity via inhibition of PLD [43] and activation of HO-1 [48]. Mice lacking D1R or D5R are hypertensive, highlighting the importance of these receptors in the regulation of blood pressure. Although the redox status of $D 1 R^{-/-}$mice remains to be determined, the hypertension in $D 5 R^{-/-}$mice is associated with increased oxidative stress related to increased pro-oxidant and decreased antioxidant activity $[43,48,49] . D 5 R^{-/-}$mice have high levels of plasma thiobarbituric acid reactive substances, a byproduct of lipid peroxidation, and renal Nox2 (gp91phox) and Nox1 (p47phox) expression. Nox activity is also increased in the brain and kidney in $D 5 R^{-/-}$mice compared to their wild-type littermates, and chronic treatment with apocynin (an NADPH oxidase inhibitor) ameliorated the increased blood pressure, plasma thiobarbituric acid reactive substances, and NADPH activity in the brain and kidney of $D 5 R^{-/}$mice [49]. In contrast, the renal expression of HO-1 is 
decreased in $D 5 R^{-/-}$mice [48,49]; these mice have increased $\alpha / \beta$ hydrolase 1 mRNA expression, possibly as a compensatory mechanism to ameliorate the increased NADPH activity [50].

Both D1R and D5R exert additional antioxidant effects by their negative regulation of the expression and function of the angiotensin II type 1 receptor (AT1R) [19], which can increase ROS production, in part, by activation of NADPH oxidase via PLC, PKC, and calcium signaling [51,52]. In rat renal proximal tubule cells the D1R inhibits AT1R function by different mechanisms depending on the duration of exposure. In the short-term (min), D1R causes a rapid partial internalization of the AT1R and complete abolition of AT1R signaling [53], while in the long-term (24 h), it decreases the total abundance of the AT1R receptor [54,55]. D5R stimulation increases the degradation of glycosylated AT1R in proteasomes in human renal proximal tubule cells consequently decreasing AT1R protein abundance [56]. Furthermore, the renal expression of AT1R is increased in $D 5 R^{-/-}$mice relative to wild-type littermates [56,57] indicating that in the basal state the constitutively active D5R decreases AT1R expression. However, decreased D1R and increased AT1R function does not necessarily cause an increase in ROS production as demonstrated in G protein-coupled receptor kinase (GRK) $4 \gamma^{142 \mathrm{~V}}$ transgenic mice which have increased blood pressure and AT1R function, as well as decreased D1R function, but normal ROS production, probably related to increased HO-1 expression [58]; hGRK $4 \gamma^{142 \mathrm{~V}}$ desensitizes the D1R but not the D5R [19,38].

\subsubsection{ROS Negatively Regulate D1-Like Receptor Expression and Function}

While D1-like receptors inhibit ROS production [19,38,42,43,45-50], the function of these receptors is impaired by oxidative stress. Renal proximal tubule cells from old rats, which have increased oxidative stress, have decreased expression of D1R [59]. Treatment with tempol, an SOD mimetic, or exercise, reduced the renal oxidative stress and normalized renal D1R expression and function in old rats [60,61]. Decreasing the oxidative stress also restored the D1R coupling to G-proteins in obese Zucker [62] and streptozotocin-treated hyperglycemic rats [63]. In obese Zucker and streptozotocin-treated hyperglycemic rats, treatment with tempol restored the D1R responses and normalized the blood pressure in obese Zucker rats [62]; streptozotocin-treated hyperglycemic rats were normotensive and their blood pressures were not affected by tempol [63]. Sprague-Dawley rats, fed high salt diet and the oxidant L-buthionine sulfoximine (glutathione synthesis inhibitor) had increased blood pressure and impaired D1R function; these effects were prevented by treatment with tempol [64]. The impairment of D1R function by oxidative stress (e.g., $\left.\mathrm{H}_{2} \mathrm{O}_{2}\right)$ in renal proximal tubule cells was mediated by the nuclear translocation of nuclear factor kappa-light-chain-enhancer of activated B cells (NF- $\mathrm{kB}$ ), activation of PKC, and translocation of GRK2 to the plasma membrane, which, in turn, caused D1R hyper-serine phosphorylation and uncoupling, thus, impairing its activity [46,65-67]. In obese Zucker rats, the D1R hyper-serine phosphorylation and uncoupling in renal proximal tubule cells was related to increased plasma membrane expression of GRK2 and total cellular expression of GRK4 [68]. GRK2 and GRK4 can impair the function of D1R [19,38]. 


\subsection{D2-Like Receptors}

\subsubsection{Renal Expression of D2-Like Dopamine Receptors}

D2 like dopamine receptors, D2R, D3R, and D4R, are all expressed in the kidney [19]. D2R is expressed in the proximal tubule, thick ascending limb, distal convoluted tubule, and cortical collecting duct in mice, rats, and humans. D2R is also expressed in the outer medullary collecting duct in rats and humans but not in mice and inner medullary collecting duct in rats but not in mice or humans. Glomerular mesangial cells in rats and glomerular podocytes in humans also express D2R. $\mathrm{D} 2 \mathrm{R}$ is not expressed in juxtaglomerular cells but may be expressed in macula densa cells in rats $[19,69]$. The long form (D2LR), rather than the short form (D2SR) of D2R, is expressed in the renal tubule [70].

D3R is expressed in the proximal tubule and distal convoluted tubule in rodents, as well as in the thick ascending limb in mice but not rats while it is expressed in the cortical collecting duct in rats but not mice. D3R is also expressed in mesangial cells and podocytes, juxtaglomerular cell and macula densa, and arterial vessels in rodents. D3R is expressed in human renal proximal tubule cells; D3R expression in other segments of the human nephron has not been reported [19]. In the rat renal proximal tubule, D3R protein is mainly located in the apical and subapical areas [71].

D4R is expressed in proximal and distal convoluted tubules [72], thick ascending limb, and cortical and outer medullary collecting ducts $[69,73]$ in rodents. D4R is also expressed in the macula densa in rats but not mice [19,74]. D4R is expressed in arterial vessels but not glomeruli in rodents. D4R protein expression in the human kidney has not been reported although D4R mRNA is expressed in the human kidney [75].

Dopamine D2-like receptors can be vasodilator or vasconstrictor, and natriuretic or antinatriuretic [19,76,77], depending on renal nerve activity or the state of sodium balance. D2-like receptor agonists also have antioxidant effects at low concentrations and have direct and/or indirect protective effects in vivo and in vitro via their antioxidant effects [78]. Ropinirole, a D2R/D3R/D4R agonist, which has the highest affinity for D2R among D2-like receptors, scavenged free radicals, suppressed lipid peroxidation but increased glutathione, catalase, and SOD activities in the striatum, and protected striatal dopaminergic neurons against 6-hydroxydopamine injury in mice. Pre-treatment with sulpiride, a D2R/D3R antagonist, prevented the antioxidant and neuroprotective effects of ropinirole [79].

\subsubsection{D2R Negatively Regulates ROS Production}

D2R agonists have neuroprotective effect against oxidative stress and scavenge free radicals [79-81], although high concentrations of $\mathrm{D} 2 \mathrm{R}$ agonist (10 $\mu \mathrm{M}$ raclopride) [82], as with D1-like receptor agonists, can also increase ROS production. In cultured rat mesencephalic neurons, pre-incubation with low concentrations of D2-like dopamine receptor agonists provided neuroprotection against glutamate-induced oxidative stress. In vivo and in vitro studies have also shown that the protective effects of D2R agonists are abolished in the presence of D2R antagonists, indicating D2R specificity $[83,84]$. By contrast, D2R antagonists can induce oxidative damage in the brain. Adult male Wistar rats treated with haloperidol had increased ROS production in the striatum and protein 
carbonyls in the hippocampus [81]. Stimulation of the D2R in neurons from rat embryonic ventral mesencephalon was protective of levodopa toxicity [84] and in mouse or human renal proximal tubule cells decreased ROS production, Nox4 expression, and NADPH oxidase activity $[19,85,86]$.

\subsubsection{D2R Protects against Oxidative Stress: Role of NADPH Oxidase}

A protective role of the $\mathrm{D} 2 \mathrm{R}$ against oxidative stress was also uncovered in mice lacking D2R $\left(D 2 R^{-/}\right)$. These mice have high blood pressure [19,87], are salt-sensitive [87], and have increased oxidative stress $[85,86,88]$, proved by increased urinary excretion of 8 -isoprostane and renal expression of Nox isoforms and activity of NADPH oxidase. Apocynin normalized the elevated blood pressure in $D 2 R^{-/}$mice. Spironolactone also normalized the high blood pressure of $D 2 R^{-/}$mice but did not normalize the renal expression of NADPH oxidase, indicating that the increased ROS production was only partly mediated by impaired aldosterone regulation [88] and that, in this model, increased ROS were involved in the development or maintenance of high blood pressure.

\subsubsection{D2R Protects against Oxidative Stress: Role of the Antioxidant, DJ-1}

The regulation of ROS production by the D2R involves not only the inhibition of pro-oxidant systems (e.g., NADPH oxidase, vide supra) but also the stimulation of antioxidant systems $[85,86,88]$. $\mathrm{D} 2 \mathrm{R}^{-/-}$mice have decreased renal expression of the antioxidant enzyme HO-2 in the kidney. HO-2 can inhibit NADPH oxidase activity [89]. The antioxidant effect of D2R also involves its interaction with two other proteins, DJ-1 (also known as Park 7) and paraoxonase 2 (PON2). DJ-1 is a protein originally described as an oncogene and identified as an autosomal-recessive gene of Parkinson disease [90]. DJ-1 is expressed in several rodent and human tissues, such as the brain, heart, kidney, liver, pancreas, and skeletal muscle [90] and its protective role against oxidative stress has been demonstrated in several disease states [91-93]. DJ-1 has intrinsic antioxidant activity as it is an atypical peroxiredoxin-like peroxidase that scavenges $\mathrm{H}_{2} \mathrm{O}_{2}$ through oxidation of Cys-106 [94] and also regulates the expression of several antioxidant genes, such as SOD [95-97]. In the absence of oxidative stress, DJ-1 binds to and represses the translation of antioxidant factors, such as SOD, and proteins involved in glutathione synthesis [98-100]. By contrast, oxidized DJ-1 dissociates from these transcripts, allowing their translation [100]. DJ-1 expression modulated astrocyte-mediated protection against neuronal oxidative stress [101] and lack of DJ-1 impaired astrocyte-mediated neuroprotection [102]. Although DJ-1 protects against neurotoxicity [103], $D J-1^{-/-}$mice did not display increased vulnerability to inflammation-related nigral degeneration, in spite of decreased antioxidant response [104]. In the brain the loss of DJ-1 function resulted in the attenuation of D2R-mediated responses without any change in receptor expression suggesting that the antioxidant effect of DJ-1 is downstream of D2R activation [105]. However, the precise function of DJ-1 in neuronal responses downstream of D2R activation remains to be defined.

DJ-1 is highly expressed in normal heart tissue. DJ-1-deficient mice subjected to oxidative stress had cardiac hypertrophy and increased susceptibility to developing heart failure [106]. DJ-1 has also been reported to protect mouse erythroid cells [107] and pancreatic $\beta$-cells [108] from oxidative damage. Indeed, oxidative stress caused by high concentrations of dopamine $(\geq 50 \mu \mathrm{M})$ has been reported to increase DJ-1 expression [28]. 
D2R and DJ-1 colocalize and coimmunoprecipitate in the mouse kidney. Mice with deletion of one $\mathrm{D} 2 \mathrm{R}$ allele $\left(D 2^{+/}\right)$or with selective renal D2R silencing are hypertensive and have increased ROS production and renal cortical expression of Nox4 but decreased expression of DJ-1 [85]. D2R can positively regulate DJ-1 expression [85] but the mechanisms by which D2R regulates the expression of DJ-1 are unknown. The negative regulation of ROS by D2R may be related to its positive regulation of DJ-1 as selective renal silencing of DJ-1 expression in mice increased NADPH oxidase activity and blood pressure [85].

\subsubsection{D2R Protects against Oxidative Stress: Role of the Antioxidant, PON2}

The antioxidant effect of D2R is mediated not only by DJ-1 but also by paraoxonase (PON). The PON family consists of three genes: PON1, PON2, and PON3. PON2 is cell associated, not found in plasma, and expressed in a variety of tissues, including the kidney, and protects against oxidative stress that may be related to hydroperoxidase activity [109-111]. Mouse peritoneal macrophages from $P O N 2^{--}$mice were reported to have increased susceptibility to urokinase plasminogen activator-induced oxidative stress [112]. Overexpression of PON2 prevented apoptosis in vascular endothelial cells [113] and inhibited the development of atherosclerosis in mice [111,114,115], via antioxidant mechanisms. Overexpression of PON2 also inhibited cell-mediated low-density lipoprotein oxidation [116]. It should be noted, however, that ROS can also increase D2R mRNA and protein expression [117], an example of negative feedback inhibition.

D2R colocalized and coimmunoprecipitated with PON2 in brush border membranes of proximal tubules of mouse kidney. Renal D2R can regulate PON2 expression because PON2 mRNA and protein expression were increased by D2R stimulation [86]. Conversely, mice lacking D2R from germline deletion or from renal selective downregulation of the gene had decreased renal PON2 protein expression. The antioxidant effect of $\mathrm{D} 2 \mathrm{R}$ was partially prevented by downregulation of PON2 indicating its participation in the antioxidant effect of the D2R. Indeed, silencing PON2 increased the expression of Nox 2 and Nox4, and NADPH oxidase activity, and completely abolished the inhibitory effect of a D2R agonist on Nox2 and Nox4 expression [86]. The increase in NADPH oxidase activity with renal silencing of DJ-1 was associated with increased ROS production and blood pressure. Therefore, the positive regulation of PON2 by D2R mediates, with DJ-1, the inhibitory effect of renal D2R on NADPH oxidase activity and ROS production. However, the mechanisms by which DJ-1 and PON2 regulate NADPH oxidase are not yet clear. It is also not known if DJ-1, PON2, and HO-2 interact but we do know that DJ-1 and PON2 do not physical interact in the kidney.

\subsubsection{D2R Protects against Oxidative Stress and Inflammation}

Oxidative stress has been extensively linked to inflammation and vice versa [118]. It is known that stimulation of NF- $\mathrm{kB}$, an important pro-inflammatory transcription factor, increases intracellular ROS production [119]. D2R agonists increased the secretion of anti-inflammatory cytokines by de novo gene expression in resting $\mathrm{T}$ lymphocytes [120], but suppressed their production in activated $\mathrm{T}$ and mast cells [121]. Silencing the D2R in mouse renal proximal tubule cells increased NF- $\mathrm{B}$ transcriptional activity, tumor necrosis factor $\alpha(\mathrm{TNF} \alpha)$, and monocyte chemoattractant protein-1 (MCP-1) levels. Selective unilateral renal D2R down-regulation in mice, in the absence of elevated 
blood pressure, reproduced the alterations in inflammatory factors and renal injury observed in $D 2 R^{-/-}$ mice, increasing the expression of several pro-inflammatory cytokines such as, TNF $\alpha, \mathrm{MCP}-1$, and MCP-2, suggesting that D2R plays a protective role against the development of renal inflammation [122]. Several human polymorphisms of $\mathrm{D} 2 \mathrm{R}$ associated with decreased expression or function of the receptor [123,124] have been associated with essential hypertension [125,126], but further studies are needed to determine if the experimental evidence for the role of the $\mathrm{D} 2 \mathrm{R}$ in the regulation of oxidative stress in hypertension can be translated to humans.

\subsection{D3R and Oxidative Stress}

The effect of D3R on ROS production is controversial. The D3R has been reported to increase an endogenous factor that has antioxidant actions and thus the D3R may have antioxidant effects, albeit indirectly [127]. Pramipexole, a selective D3R agonist, protected against free-radical induced cytotoxicity, inhibited lipid peroxidation in neurons [128], increased the activity of antioxidant enzymes (glutathione peroxidase and catalase) and inhibited the production of ROS by the mitochondria, however, these effects were independent of D3R activation [129,130]. In contrast, pretreatment with D-264, a D3R agonist, prevented neurotoxin- and lactacystin-induced neurodegeneration, effects that were lost in the presence of a D3R antagonist [131], indicating that the D3R has antioxidant effects.

Disruption of the $\mathrm{D} 3 \mathrm{R}$ gene in mice $\left(D 3 R^{-/-}\right)$caused renin-dependent hypertension that was associated with decreased ability to excrete an acute intravenous and chronic dietary salt load [132]. However, the hypertension and salt sensitivity in $D 3 R^{-/-}$mice were not associated with increased renal oxidative stress as demonstrated by normal renal expression of Nox isoforms and nitrotyrosine, as well as normal urinary excretion of 8-isoprostane. The expression of renal D5R, which has antioxidant property $[43,45,48,49]$, was increased in $D 3 R^{-/-}$mice suggesting that compensatory mechanisms may be involved in maintaining a normal production of ROS in these mice [133].

\subsection{D4R and Oxidative Stress}

Some of the neuroprotective effects of D4R agonists are apparently independent of any action on ROS [134]. However, the D4R antagonist L-745,870 has been reported to decrease the vulnerability of neuronal and non-neuronal cells to oxidative stress-induced apoptosis [135]. By contrast, the activation of D4R has been reported to protect against hypoxia/reoxygenation-induced oxidative stress and cell death in HT22 cells derived from mouse hippocampal neurons [136]. In addition, the protective effects of dopamine and D4R agonist on glutamate-induced ROS production were antagonized by a D4R antagonist [137]. However, mice lacking D4R have increased blood pressure, in part caused by increased AT1R expression [138], but there was no evidence for an increase in oxidative stress in these mice.

\section{Summary}

Physiological concentrations of dopamine have protective effects on oxidative stress in the kidney. D1R, D2R, and D5R inhibit NADPH oxidase activity and ROS production and are needed to keep a normal redox balance (Table 1, Figure 1). D1R inhibits NADPH oxidase activity via PKA and PKC cross-talk and stimulates SOD, glutathione peroxidase, and glutamylcysteine transferase. The D5R 
decreases NADPH oxidase activity, in part by inhibiting PLD2 and increasing the expression of HO-1, an antioxidant. The D2R also decreases ROS production by increasing the expression of the antioxidants DJ-1, PON2, and HO-2. Lack of any of the dopamine receptor subtypes results in increased blood pressure that is not always associated with increased oxidative stress. Whether or not D3R and D4R protect against oxidative stress remains to be determined; the hypertension in mice lacking D3R and D4R is not associated with oxidative stress.

Table 1. Dopamine receptor subtypes D1R, D2R, and D5R regulate the production of reactive oxygen species by inhibiting pro-oxidant and stimulating antioxidant enzymes.

\begin{tabular}{ccc}
\hline Dopamine receptor subtype & Pro-oxidant enzymes (inhibition) & Anti-oxidant enzymes (stimulation) \\
\hline D1R & $\begin{array}{c}\text { NADPH oxidase, via PKA/PKC } \\
\text { cross talk [19,45,47] }\end{array}$ & $\begin{array}{c}\text { SOD, glutathione peroxidase, glutamyl } \\
\text { cysteine transferase, and HO-1 [46,65] }\end{array}$ \\
\hline D2R & NADPH oxidase [19,85,86,88] & $\begin{array}{c}\text { DJ-1, PON2, and HO-2 [19,85,86] } \\
\text { glutathione, catalase, and SOD [79] }\end{array}$ \\
\hline D5R & NADPH oxidase, via PLD2 [43,49] & $\begin{array}{c}\text { SOD, glutathione peroxidase, glutamyl } \\
\text { cysteine transferase, and HO-1 [46,48] }\end{array}$ \\
\hline
\end{tabular}

Figure 1. D1R, D2R, and D5R inhibit NADPH oxidase activity and decrease ROS production in the kidney. D1R inhibits NADPH oxidase activity via PKC/PKA pathway (and pathways similar to D5R, see Table 1). D5R inhibits the expression of PLD2 and therefore, NADPH oxidase and increases the expression of HO-1, which also inhibits NADPH oxidase activity. D2R increases HO-2, DJ-1, and PON2 expression, all of which inhibit NAPDH oxidase activity. D2R inhibits TNF $\alpha$ expression and NFkB activity. HO-1, HO-2, DJ-1, and PON2 have antioxidant properties. AT1R increases NADPH oxidase activity. D3R and D4R do not directly affect ROS production.

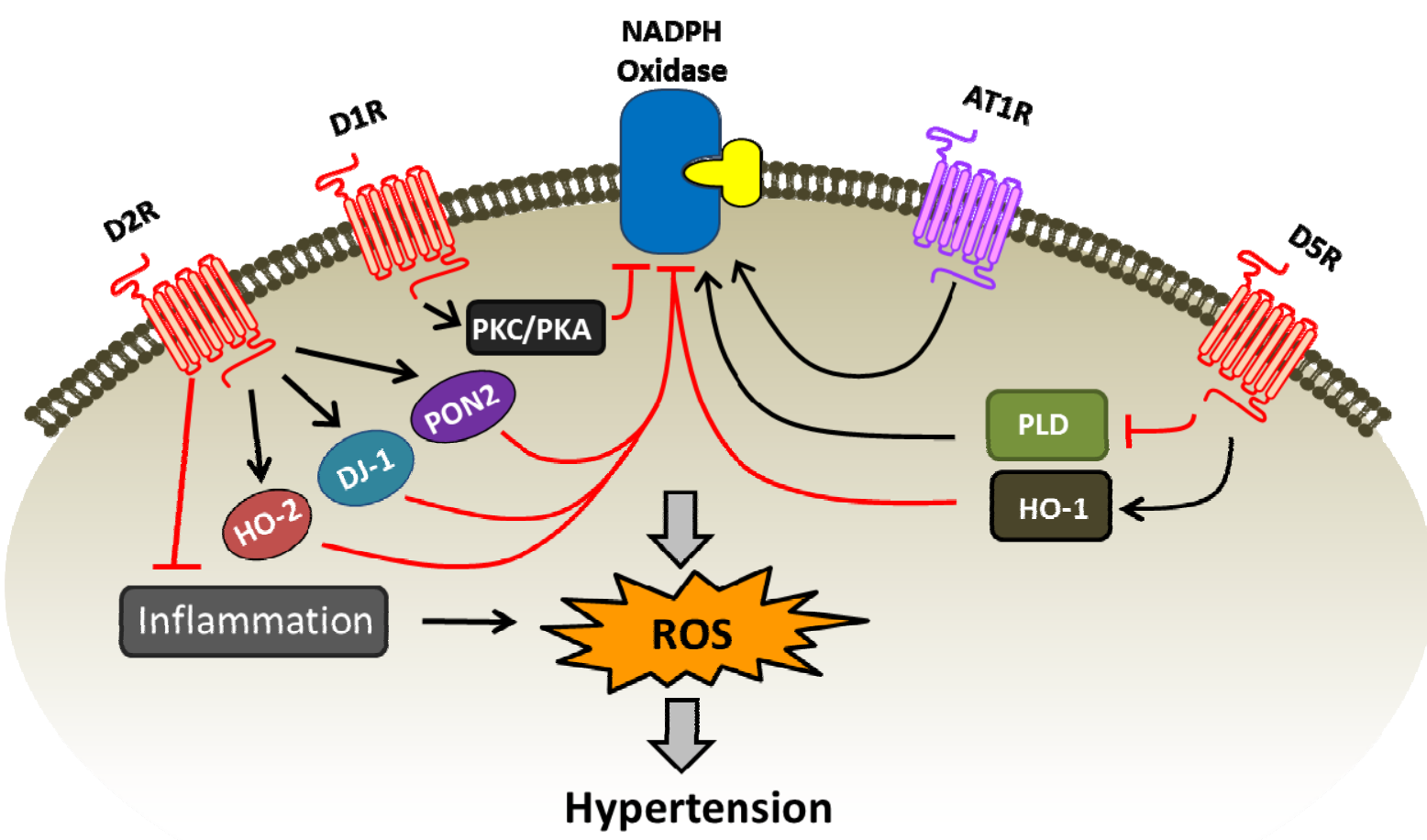




\section{Acknowledgments}

This work was supported by grants from the National Institutes of Health, HL023081, DK039308, HL074940, HL068686, HL092196, and DK090918.

\section{Conflicts of Interest}

There are no conflicts of interest.

\section{References}

1. Prosser, B.L.; Ward, C.W.; Lederer, W.J. X-ROS signaling: Rapid mechano-chemo transduction in heart. Science 2011, 333, 1440-1445.

2. Rhee, S.G. Cell signaling. $\mathrm{H}_{2} \mathrm{O}_{2}$, a necessary evil for cell signaling. Science 2006, 312, 1882-1883.

3. Ristow, M.; Zarse, K. How increased oxidative stress promotes longevity and metabolic health: The concept of mitochondrial hormesis (mitohormesis). Exp. Gerontol. 2010, 45, 410-418.

4. Bretón-Romero, R.; Lamas, S. Hydrogen Peroxide signaling mediator in the activation of p38 MAPK in vascular endothelial cells. Methods Enzymol. 2013, 528, 49-59.

5. Chung, H.S.; Wang, S.B.; Venkatraman, V.; Murray, C.I.; van Eyk, J.E. Cysteine oxidative posttranslational modifications: Emerging regulation in the cardiovascular system. Circ. Res. 2013, 112, 382-392.

6. Evans, J.L.; Goldfine, I.D.; Maddux, B.A.; Grodsky, G.M. Are oxidative stress-activated signaling pathways mediators of insulin resistance and $\beta$-cell dysfunction? Diabetes 2003, 52, 1-8.

7. Lassègue, B.; San Martín, A.; Griendling, K.K. Biochemistry, physiology, and pathophysiology of NADPH oxidases in the cardiovascular system. Circ. Res. 2012, 110, 1364-1390.

8. Sedeek, M.; Hébert, R.L.; Kennedy, C.R.; Burns, K.D.; Touyz, R.M. Molecular mechanisms of hypertension: Role of Nox family NADPH oxidases. Curr. Opin. Nephrol. Hypertens. 2009, 18, $122-127$.

9. Chen, F.; Haigh, S.; Barman, S.; Fulton, D.J. From form to function: The role of Nox4 in the cardiovascular system. Front. Physiol. 2012, 3, 1-12.

10. Lo, J.; Patel V.B.; Wang, Z.; Levasseur, J.; Kaufman, S.; Penninger, J.M.; Oudit G.Y. Angiotensin-converting enzyme 2 antagonizes angiotensin II-induced pressor response and NADPH oxidase activation in Wistar-Kyoto rats and spontaneously hypertensive rats. Exp. Physiol. 2013, 98, 109-122.

11. Wilcox, C.S. Asymmetric dimethylarginine and reactive oxygen species: Unwelcome twin visitors to the cardiovascular and kidney disease tables. Hypertension 2012, 59, 375-381.

12. Wingler, K.; Wunsch, S.; Kreutz, R.; Rothermund, L.; Paul, M.; Schmidt, H.H. Upregulation of the vascular NAD(P)H oxidase isoforms Nox1 and Nox4 by the renin-angiotensin system in vitro and in vivo. Free Radic. Biol. Med. 2001, 31, 1456-1464. 
13. Wind, S.; Beuerlein, K.; Armitagr, E.; Taye, A.; Kumar, H.; Janowitz, D.; Neff, C.; Shar, M.; Wingler, K.; Schmidt, H.H. Oxidative stress and endothelial dysfunction in aortas of aged spontaneously hypertensive rats by NOX1/2 is reversed by NADPH oxidase inhibition. Hypertension 2010, 56, 490-497.

14. Yu, P.Y.; Han, W.X.; Zhang, Y.R.; Villar, V.A.M.; Li, H.W.; Felder, R.A.; Jose, P.A. NADPH oxidase 5 may play a role in human essential hypertension. Free Radic. Biol. Med. 2011, 51 , S53.

15. Manea, A. NADPH oxidase-derived reactive oxygen species: Involvement in vascular physiology and pathology. Cell Tissue Res. 2010, 342, 325-339.

16. Morigi, M.; Macconi, D.; Zoja, C.; Donadelli, R.; Buelli, S.; Zanchi, C.; Ghilardi, M.; Remuzzi, G. Protein overload-induced NF- $\kappa$ B activation in proximal tubular cells requires $\mathrm{H}_{2} \mathrm{O}_{2}$ through a PKC-dependent pathway. J. Am. Soc. Nephrol. 2002, 13, 1179-1189.

17. Li, H.; Han, W.; Villar, V.A.; Keever, L.B.; Lu, Q.; Hopfer, U.; Quinn, M.T.; Felder, R.A.; Jose, P.A.; Yu, P. D1-like receptors regulate NADPH oxidase activity and subunit expression in lipid raft microdomains of renal proximal tubule cells. Hypertension 2009, 53, 1054-1061.

18. Han, W.; Li, H.; Villar, V.A.; Pascua, A.M.; Dajani, M.I.; Wang, X.; Natarajan, A.; Quinn, M.T.; Felder, R.A.; Jose, P.A.; Yu, P. Lipid rafts keep NADPH oxidase in the inactive state in human renal proximal tubule cells. Hypertension 2008, 51, 481-487.

19. Armando, I.; Villar, V.A.; Jose, P.A. Dopamine and renal function and blood pressure regulation. Compr. Physiol. 2011, 1, 1075-1117.

20. Zhang, M.Z.; Yao, B.; Wang, S.; Fan, X.; Wu, G.; Yang, H.; Yin, H.; Yang, S.; Harris, R.C. Intrarenal dopamine deficiency leads to hypertension and decreased longevity in mice. J. Clin. Invest. 2011, 121, 2845-2854.

21. Zhang, M.Z.; Yao, B.; Yang, S.; Yang, H.; Wang, S.; Fan, X.; Yin, H.; Fogo, A.B.; Moeckel, G.W.; Harris, R.C. Intrarenal dopamine inhibits progression of diabetic nephropathy. Diabetes 2012, 61, 2575-2584.

22. Souza, B.R.; Romano-Silva, M.A.; Tropepe, V. Dopamine D2 receptor activity modulates Akt signaling and alters GABAergic neuron development and motor behavior in zebrafish larvae. J. Neurosci. 2011, 31, 5512-5525.

23. Pollack, A. Coactivation of D1 and D2 dopamine receptors: in marriage, a case of his, hers, and theirs. Sci. STKE 2004, 255, pe50.

24. Yu, P.Y.; Asico, L.D.; Eisner, G.M.; Jose, P.A. Differential regulation of renal phospholipase C isoforms by catecholamines. J. Clin. Invest. 1995, 95, 304-308.

25. Yu, P.Y.; Eisner, G.M.; Yamaguchi, I.; Mouradian, M.M.; Felder, R.A.; Jose, P.A. Dopamine D1A receptor regulation of phospholipase C isoform. J. Biol. Chem. 1996, 271, 19503-19508.

26. Yao, B.; Harris, R.C.; Zhang, M.Z. Intrarenal dopamine attenuates deoxycorticosterone acetate/high salt-induced blood pressure elevation in part through activation of a medullary cyclooxygenase 2 pathway. Hypertension 2009, 54, 1077-1083.

27. Cosentino, M.; Rasini, E.; Colombo, C.; Marino, F.; Blandini, F.; Ferrari, M.; Samuele, A.; Lecchini, S.; Nappi, G.; Frigo, G. Dopaminergic modulation of oxidative stress and apoptosis in human peripheral blood lymphocytes: Evidence for a D1-like receptor-dependent protective effect. Free Radic. Biol. Med. 2004, 36, 1233-1240. 
28. Lev, N.; Ickowicz, D.; Barhum, Y.; Lev, S.; Melamed, E.; Offen, D. DJ-1 protects against dopamine toxicity. J. Neural Transm. 2009, 116, 151-160.

29. Luo, Y.; Roth, G.S. The roles of dopamine oxidative stress and dopamine receptor signaling in aging and age-related neurodegeneration. Antioxid. Redox Signal. 2000, 2, 449-460.

30. Eibl, J.K.; Abdallah, Z.; Ross, G.M. Zinc-metallothionein: A potential mediator of antioxidant defence mechanisms in response to dopamine-induced stress. Can. J. Physiol. Pharmacol. 2010, $88,305-312$.

31. Amenta, F.; Barili, P.; Bronzetti, E.; Ricci, A. Dopamine D1-like receptor subtypes in the rat kidney: A microanatomical study. Clin. Exp. Hypertens. 1999, 21, 17-23.

32. O’Connell, D.P.; Botkin, S.J.; Ramos, S.I.; Sibley, D.R.; Ariano, M.A.; Felder, R.A.; Carey, R.M. Localization of dopamine D1A receptor protein in rat kidneys. Am. J. Physiol. 1995, 268, F1185-F1197.

33. Wang, X.; Villar, V.A.; Armando, I.; Eisner, G.M.; Felder, R.A.; Jose P.A. Dopamine, kidney, and hypertension: Studies in dopamine receptor knockout mice. Pediatr. Nephrol. 2008, 23, 2131-2146.

34. Bek, M.; Fischer, K.G.; Greiber, S.; Hupfer, C.; Mundel, P.; Pavenstädt, H. Dopamine depolarizes podocytes via a D1-like receptor. Nephrol. Dial. Transplant. 1999, 14, 581-587.

35. Yamaguchi, I.; Yao, L.; Sanada, H.; Ozono, R.; Mouradian, M.M.; Jose, P.A.; Carey, R.M.; Felder, R.A. Dopamine D1A receptors and renin release in rat juxtaglomerular cells. Hypertension 1997, 29, 962-968.

36. O’Connell, D.P.; Aherne, A.M.; Lane, E.; Felder, R.A.; Carey, R.M. Detection of dopamine receptor D1A subtype-specific mRNA in rat kidney by in situ amplification. Am. J. Physiol. 1998, 274, F232-F341.

37. Ozono, R.; O’Connell, D.P.; Wang, Z.Q.; Moore, A.F.; Sanada, H.; Felder, R.A.; Carey, R.M. Localization of the dopamine D1 receptor protein in the human heart and kidney. Hypertension 1997, 30, 725-729.

38. Jose, P.A.; Soares-da-Silva, P.; Eisner, G.M., Felder, R.A. Dopamine and G protein-coupled receptor kinase 4 in the kidney: Role in blood pressure regulation. Biochim. Biophys. Acta 2010, 1802, 1259-1267.

39. Moussa, C.E.; Tomita, Y.; Sidhu, A. Dopamine D1 receptor-mediated toxicity in human SK-N-MC neuroblastoma cells. Neurochem. Int. 2006, 48, 226-234.

40. Yu, Y.; Wang, J.R.; Sun, P.H.; Guo, Y.; Zhang, Z.J.; Jin, G.Z.; Zhen, X. Neuroprotective effects of atypical D1 receptor agonist SKF83959 are mediated via D1 receptor-dependent inhibition of glycogen synthase kinase-3 beta and a receptor-independent anti-oxidative action. J. Neurochem. 2008, 104, 946-956.

41. Yasunari, K.; Kohno, M.; Hasuma, T.; Horio, T.; Kano, H.; Yokokawa, K.; Minami. M.; Yoshikawa, J. Dopamine as a novel antimigration and antiproliferative factor of vascular smooth muscle cells through dopamine D1-like receptors. Arterioscler. Thromb. Vasc. Biol. 1997, 17, 3164-3173.

42. Noh, J.S.; Gwag, B.J. Attenuation of oxidative neuronal necrosis by a dopamine D1 agonist in mouse cortical cell cultures. Exp. Neurol. 1997, 146, 604-608. 
43. Yang, Z.; Asico, L.D.; Yu, P.; Wang, Z.; Jones, J.E., Bai, R.K.; Sibley, D.R.; Felder, R.A.; Jose, P.A. D5 dopamine receptor regulation of phospholipase D. Am. J. Physiol. Heart. Circ. Physiol. 2005, 288, H55-H61.

44. Li, G.Y.; Li, T.; Fan, B.; Zheng, Y.C.; Ma, T.H. The $\mathrm{D}_{1}$ dopamine receptor agonist, SKF83959, attenuates hydrogen peroxide-induced injury in RGC-5 cells involving the extracellular signal-regulated kinase/p38 pathways. Mol. Vis. 2012, 18, 2882-2895.

45. Yasunari, K.; Kohno, M.; Kano, H.; Minami, M.; Yoshikawa, J. Dopamine as a novel antioxidative agent for rat vascular smooth muscle cells through dopamine $\mathrm{D}_{1}$-like receptors. Circulation 2000, 101, 2302-2308.

46. George, L.E.; Lokhandwala, M.F.; Asghar, M. Novel role of NF-kB-p65 in antioxidant homeostasis in human kidney. Am. J. Physiol. Renal Physiol. 2012, 302, F1440-F1446.

47. Yu, P.; Han, W.X.; Sun, M.; Villar, V.A.M.; Jose, P.A. Protein kinase C inhibits NADPH oxidase activity via cross-talk with protein kinase A in HEK-293 heterologously expressing D1 receptor cells. J. Am. Soc. Nephrol. 2009, 20, 533A.

48. Lu, Q.; Yang, Y.; Villar, V.A.; Asico, L.; Jones, J.E.; Yu, P.; Li, H.; Weinman, E.J.; Eisner, G.M.; Jose, P.A. D5 dopamine receptor decreases NADPH oxidase, reactive oxygen species and blood pressure via heme oxygenase-1. Hypertens. Res. 2013, 36, 684-690.

49. Yang, Z.; Asico, L.D.; Yu, P.; Wang, Z.; Jones, J.E.; Escano, C.S.; Wang, X.; Quinn, M.T.; Sibley, D.R.; Romero, G.G.; Felder, R.A.; Jose, P.A. D5 dopamine receptor regulation of reactive oxygen species production, NADPH oxidase, and blood pressure. Am. J. Physiol. Regul. Integr. Comp. Physiol. 2006, 290, R96-R104.

50. Stoelting, M.; Geyer, M.; Reuter, S.; Reichelt, R.; Bek, M.J.; Pavenstädt, H. $\alpha / \beta$ hydrolase 1 is upregulated in D5 dopamine receptor knockout mice and reduces $\mathrm{O}_{2}{ }^{-}$production of NADPH oxidase. Biochem. Biophys. Res. Commun. 2009, 379, 81-85.

51. Onozato, M.L.; Tojo, A.; Kobayashi, N.; Goto, A.; Matsuoka, H.; Fujita, T. Dual blockade of aldosterone and angiotensin II additively suppresses TGF- $\beta$ and NADPH oxidase in the hypertensive kidney. Nephrol. Dial. Transplant. 2007, 22, 1314-1322.

52. Fazeli, G.; Stopper, H.; Schinzel, R.; Ni, C.W.; Jo, H.; Schupp, N. Angiotensin II induces DNA damage via AT1 receptor and NADPH oxidase isoform Nox4. Mutagenesis 2012, 27, 673-681.

53. Khan, F.; Spicarová, Z.; Zelenin, S.; Holtbäck, U.; Scott, L.; Aperia, A. Negative reciprocity between angiotensin II type 1 and dopamine D1 receptors in rat renal proximal tubule cells. Am. J. Physiol. Renal Physiol. 2008, 295, F1110-F1116.

54. Zeng, C.; Luo, Y.; Asico, L.D.; Hopfer, U.; Eisner, G.M.; Felder, R.A.; Jose, P.A. Perturbation of D1 dopamine and AT1 receptor interaction in spontaneously hypertensive rats. Hypertension 2003, 42, 787-792.

55. Zeng, C.; Wang, Z.; Hopfer, U.; Asico, L.D.; Eisner, G.M.; Felder, R.A.; Jose, P.A. Rat strain effects of AT1 receptor activation on D1 dopamine receptors in immortalized renal proximal tubule cells. Hypertension 2005, 46, 799-805.

56. Li, H.; Armando, I.; Yu, P.; Escano, C.; Mueller, S.C.; Asico, L.; Pascua, A.; Lu, Q.; Wang, X.; Villar, V.A.; et al. Dopamine 5 receptor mediates Ang II type 1 receptor degradation via a ubiquitin-proteasome pathway in mice and human cells. J. Clin. Invest. 2008, 118, 2180-2189. 
57. Zeng, C.; Yang, Z.; Wang, Z.; Jones, J.; Wang, X.; Altea, J.; Mangrum, A.J.; Hopfer, U.; Sibley, D.R.; Eisner, G.M.; et al. Interaction of angiotensin II type 1 and D5 dopamine receptors in renal proximal tubule cells. Hypertension 2005, 45, 804-810.

58. Wang, Z.; Armando, I.; Asico, L.D., Escano, C.; Wang, X.; Lu, Q.; Felder R.A.; Schnackenberg, C.G.; Sibley, D.R.; Eisner, G.M.; et al. The elevated blood pressure of human GRK4gamma A142V transgenic mice is not associated with increased ROS production. Am. J. Physiol. Heart. Circ. Physiol. 2007, 292, H2083-H2092.

59. Asghar, M.; Chillar, A.; Lokhandwala, M.F. Renal proximal tubules from old Fischer 344 rats grow into epithelial cells in cultures and exhibit increased oxidative stress and reduced D1 receptor function. Am. J. Physiol. Cell Physiol. 2008, 295, C1326-C1331.

60. Fardoun, R.Z.; Asghar, M.; Lokhandwala, M. Role of oxidative stress in defective renal dopamine D1 receptor-G protein coupling and function in old Fischer 344 rats. Am. J. Physiol. Renal Physiol. 2006, 291, F945-F951.

61. Asghar, M.; George, L.; Lokhandwala, M.F. Exercise decreases oxidative stress and inflammation and restores renal dopamine D1 receptor function in old rats. Am. J. Physiol. Renal Physiol. 2007, 293, F914-F919.

62. Banday, A.A.; Marwaha, A.; Tallam, L.S.; Lokhandwala, M.F. Tempol reduces oxidative stress, improves insulin sensitivity, decreases renal dopamine D1 receptor hyperphosphorylation, and restores D1 receptor-G-protein coupling and function in obese Zucker rats. Diabetes 2005, 54, 2219-2226.

63. Marwaha, A.; Lokhandwala, M.F. Tempol reduces oxidative stress and restores renal dopamine D1-like receptor-G protein coupling and function in hyperglycemic rats. Am. J. Physiol. Renal Physiol. 2006, 291, F58-F66.

64. Banday, A.A.; Fazili, F.R.; Lokhandwala, M.F. Oxidative stress causes renal dopamine D1 receptor dysfunction and hypertension via mechanisms that involve nuclear factor-kappaB and protein kinase C. J. Am. Soc. Nephrol. 2007, 18, 1446-1457.

65. George, L.; Lokhandwala, M.F.; Asghar, M. Exercise activates redox-sensitive transcription factors and restores renal D1 receptor function in old rats. Am. J. Physiol. Renal Physiol. 2009, 297, F1174-F1180.

66. Banday, A.A.; Lokhandwala, M.F. Oxidative stress reduces renal dopamine D1 receptor-Gq/11alpha $\mathrm{G}$ protein-phospholipase $\mathrm{C}$ signaling involving $\mathrm{G}$ protein-coupled receptor kinase 2. Am. J. Physiol. Renal Physiol. 2007, 293, F306-F315.

67. Asghar, M.; Banday, A.A.; Fardoun, R.Z.; Lokhandwala, M.F. Hydrogen peroxide causes uncoupling of dopamine D1-like receptors from $\mathrm{G}$ proteins via a mechanism involving protein kinase C and G-protein-coupled receptor kinase 2. Free Radic. Biol. Med. 2006, 40, 13-20.

68. Trivedi, M.; Lokhandwala, M.F. Rosiglitazone restores renal D1A receptor-Gs protein coupling by reducing receptor hyperphosphorylation in obese rats. Am. J. Physiol. Renal Physiol. 2005, 289, F298-F304.

69. Shin, Y.; Kumar, U.; Patel, Y.; Patel, S.C.; Sidhu, A. Differential expression of D2-like dopamine receptors in the kidney of the spontaneously hypertensive rat. J. Hypertens. 2003, 21, 199-207. 
70. Gao, D.Q.; Canessa, L.M.; Mouradian, M.M.; Jose, P.A. Expression of the D2 subfamily of dopamine receptor genes in kidney. Am. J. Physiol. 1994, 266, F646-F650.

71. Nurnberger, A.; Rabiger, M.; Mack, A.; Diaz, J.; Sokoloff, P.; Muhlbauer, B.; Luippold, G. Subapical localization of the dopamine D3 receptor in proximal tubules of the rat kidney. J. Histochem. Cytochem. 2004, 52, 1647-1655.

72. Ricci, A.; Marchal-Victorion, S.; Bronzetti, E.; Parini, A.; Amenta, F.; Tayebati, S.K. Dopamine D4 receptor expression in rat kidney: Evidence for pre- and postjunctional localization. J. Histochem. Cytochem. 2002, 50, 1091-1096.

73. Sun, D.; Wilborn, T.W.; Schafer, J.A. Dopamine D4 receptor isoform mRNA and protein are expressed in the rat cortical collecting duct. Am. J. Physiol. 1998, 275, F742-F751.

74. Sanada, H.; Yao, L.; Jose, P.A.; Carey, R.M.; Felder, R.A. Dopamine D3 receptors in rat juxtaglomerular cells. Clin. Exp. Hypertens. 1997, 19, 93-105.

75. Matsumoto, M.; Hidaka, K.; Tada, S.; Tasaki, Y.; Yamaguchi, T. Full-length cDNA cloning and distribution of human dopamine D4 receptor. Brain Res. Mol. Brain Res. 1995, 29, 157-162.

76. Wiederkehr, M.R.; di Sole, F.; Collazo, R.; Quiñones, H.; Fan, L.; Murer, H.; Helmle-Kolb, C.; Moe, O.W. Characterization of acute inhibition of $\mathrm{Na} / \mathrm{H}$ exchanger NHE-3 by dopamine in opossum kidney cells. Kidney Int. 2001, 59, 197-209.

77. Eklof, A.C. The natriuretic response to a dopamine DA1 agonist requires endogenous activation of dopamine DA2 receptors. Acta Physiol. Scand. 1997, 160, 311-314.

78. Kitamura, Y.; Taniguchi, T.; Shimohama, S.; Akaike, A.; Nomura, Y. Neuroprotective mechanisms of antiparkinsonian dopamine D2-receptor subfamily agonists. Neurochem. Res. 2003, 28, 1035-1040.

79. Iida, M.; Miyazaki, I.; Tanaka, K.; Kabuto, H.; Iwata-Ichikawa, E.; Ogawa, N. Dopamine D2 receptor-mediated antioxidant and neuroprotective effects of ropinirole, a dopamine agonist. Brain Res. 1999, 838, 51-59.

80. Ogawa, N.; Tanaka, K.; Asanuma, M.; Kawai, M.; Masumizu, T.; Kohno, M.; Mori, A. Bromocriptine protects mice against 6-hydroxydopamine and scavenges hydroxyl free radicals in vitro. Brain Res. 1994, 657, 207-213.

81. Polydoro, M.; Schröder, N.; Lima M.N., Caldana, F.; Laranja, D.C.; Bromberg, E.; Roesler, R.; Quevedo, J.; Moreira, J.C.; Dal-Pizzol, F. Haloperidol- and clozapine-induced oxidative stress in the rat brain. Pharmacol. Biochem. Behav. 2004, 78, 751-756.

82. Charvin, D.; Vanhoutte, P.; Pagès, C.; Borrelli, E.; Caboche, J. Unraveling a role for dopamine in Huntington's disease: The dual role of reactive oxygen species and D2 receptor stimulation. Proc. Natl. Acad. Sci. USA. 2005, 102, 12218-12223.

83. Sawada, H.; Ibi, M.; Kihara, T.; Urushitani, M.; Akaike, A.; Kimura, J.; Shimohama, S. Dopamine D2-type agonists protect mesencephalic neurons from glutamate neurotoxicity: Mechanisms of neuroprotective treatment against oxidative stress. Ann. Neurol. 1998, 44, $110-118$.

84. Takashima, H.; Tsujihata, M.; Kishikawa, M.; Freed, W.J. Bromocriptine protects dopaminergic neurons from levodopa-induced toxicity by stimulating $\mathrm{D}_{2}$ receptors. Exp. Neurol. 1999, 159, 98-104. 
85. Cuevas, S.; Zhang, Y.; Yang, Y.; Escano, C.; Asico, L.; Jones, J.E.; Armando, I.; Jose, P.A. Role of renal DJ-1 in the pathogenesis of hypertension associated with increased reactive oxygen species production. Hypertension 2012, 59, 446-452.

86. Yang, Y.; Zhang, Y.; Cuevas, S.; Villar, V.A.; Escano, C.; Asico, L.D.; Yu, P.; Grandy, D.K.; Felder, R.A.; Armando, I.; et al. Paraoxonase 2 decreases renal reactive oxygen species production, lowers blood pressure, and mediates dopamine D2 receptor-induced inhibition of NADPH oxidase. Free Radic. Biol. Med. 2012, 53, 437-446.

87. Ueda, A.; Ozono, R.; Oshima, T.; Yano, A.; Kambe, M.; Teranishi, Y.; Katsuki, M.; Chayama, K. Disruption of the type 2 dopamine receptor gene causes a sodium-dependent increase in blood pressure in mice. Am. J. Hypertens. 2003, 16, 853-858.

88. Armando, I.; Wang, X.; Villar, V.A.; Jones, J.E.; Asico, L.D.; Escano, C.; Jose, P.A. Reactive oxygen species-dependent hypertension in dopamine D2 receptor-deficient mice. Hypertension 2007, 49, 672-678.

89. Bellner, L.; Martinelli, L.; Halilovic, A.; Patil, K.; Puri, N.; Dunn, M.W.; Regan, R.F.; Schwartzman, M.L. Heme oxygenase-2 deletion causes endothelial cell activation marked by oxidative stress, inflammation, and angiogenesis. J. Pharmacol. Exp. Ther. 2009, 331, 925-932.

90. Nagakubo, D.; Taira, T.; Kitaura, H.; Ikeda, M.; Tamai, K.; Iguchi-Ariga, S.M.; Ariga, H. DJ-1, a novel oncogene which transforms mouse NIH3T3 cells in cooperation with ras. Biochem. Biophys. Res. Commun. 1997, 231, 509-513.

91. Martinat, C.; Shendelman, S.; Jonason, A.; Leete, T.; Beal, M.F.; Yang, L.; Floss, T.; Abeliovich, A. Sensitivity to oxidative stress in DJ-1-deficient dopamine neurons: An ES- derived cell model of primary Parkinsonism. PLoS Biol. 2004, 2, e327.

92. Taira, T.; Saito, Y.; Niki, T.; Iguchi-Ariga, S.M.; Takahashi, K.; Ariga, H. DJ-1 has a role in antioxidative stress to prevent cell death. EMBO Rep. 2004, 5, 213-218.

93. Aleyasin, H.; Rousseaux, M.W., Phillips, M.; Kim, R.H.; Bland, R.J.; Callaghan, S.; Slack, R.S.; During, M.J.; Mak, T.W.; Park, D.S. The Parkinson's disease gene DJ-1 is also a key regulator of stroke-induced damage. Proc. Natl. Acad. Sci. USA 2007, 104, 18748-18753.

94. Andres-Mateos, E.; Perier, C.; Zhang, L.; Blanchard-Fillion, B.; Greco, T.M.; Thomas, B.; Ko, H.S.; Sasaki, M.; Ischiropoulos, H.; Przedborski, S.; et al. DJ-1 gene deletion reveals that DJ-1 is an atypical peroxiredoxin-like peroxidase. Proc. Natl. Acad. Sci. USA 2007, 104, 14807-14812.

95. Liu, F.; Nguyen J.L.; Hulleman J.D.; Li, L.; Rochet, J.C. Mechanisms of DJ-1 neuroprotection in a cellular model of Parkinson's disease. J. Neurochem. 2008, 105, 2435-2453.

96. Zhou, W.; Freed, C.R. DJ-1 up-regulates glutathione synthesis during oxidative stress and inhibits A53T alpha-synuclein toxicity. J. Biol. Chem. 2005, 280, 43150-43158.

97. Zhong, N.; Xu, J. Synergistic activation of the human MnSOD promoter by DJ-1 and PGC-1alpha: Regulation by SUMOylation and oxidation. Hum. Mol. Genet. 2008, 17, 3357-3367.

98. Vasseur, S.; Afzal, S.; Tardivel-Lacombe, J.; Park, D.S.; Iovanna, J.L.; Mak, T.W. DJ-1/PARK7 is an important mediator of hypoxia-induced cellular responses. Proc. Natl. Acad. Sci. USA 2009, 106, 1111-1116. 
99. Fan, J.; Ren, H.; Jia, N.; Fei, E.; Zhou, T.; Jiang, P.; Wu, M.; Wang, G. DJ-1 decreases Bax expression through repressing p53 transcriptional activity. J. Biol. Chem. 2008, 283, 4022-4030.

100. Van der Brug, M.P., Blackinton, J.; Chandran, J.; Hao, L.Y.; Lal, A.; Mazan-Mamczarz, K.; Martindale, J.; Xie, C.; Ahmad, R.; Thomas, K.J.; et al. RNA binding activity of the recessive parkinsonism protein DJ-1 supports involvement in multiple cellular pathways. Proc. Natl. Acad. Sci. USA 2008, 105, 10244-10249.

101. Mullett, S.J.; di Maio, R.; Greenamyre, J.T.; Hinkle, D.A. DJ-1 expression modulates astrocyte-mediated protection against neuronal oxidative stress. J. Mol. Neurosci. 2013, 49, 507-511.

102. Lev, N.; Barhum, Y.; Ben-Zur, T.; Melamed, E.; Steiner, I.; Offen, D. Knocking out DJ-1 attenuates astrocytes neuroprotection against 6-hydroxydopamine toxicity. J. Mol. Neurosci. 2013, 50, 542-550.

103. Sun, S.Y.; An, C.N.; Pu, X.P. DJ-1 protein protects dopaminergic neurons against 6-OHDA/MG-132-induced neurotoxicity in rats. Brain Res. Bull. 2012, 88, 609-616.

104. Nguyen, T.A.; Frank-Cannon, T.; Martinez, T.N.; Ruhn, K.A.; Marvin, M.; Casey, B.; Treviño, I.; Hong, J.J.; Goldberg, M.S.; Tansey, M.G. Analysis of inflammation-related nigral degeneration and locomotor function in DJ-1 ${ }^{-/-}$mice. J. Neuroinflamm. 2013, 10, 50.

105. Goldberg, M.S.; Pisani, A.; Haburcak, M.; Vortherms, T.A.; Kitada, T.; Costa, C.; Tong, Y.; Martella, G.; Tscherter, A.; Martins, A.; et al. Nigrostriatal dopaminergic deficits and hypokinesia caused by inactivation of the familial Parkinsonism-linked gene DJ-1. Neuron 2005, 45, 489-496.

106. Billia, F.; Hauck, L.; Grothe, D.; Konecny, F.; Rao, V.; Kim, R.H.; Mak, T.W. Parkinson-susceptibility gene DJ-1/PARK7 protects the murine heart from oxidative damage in vivo. Proc. Natl. Acad. Sci. USA 2013, 110, 6085-6090.

107. Xu, X.; Martin, F.; Friedman, J.S. The familial Parkinson's disease gene DJ-1 (PARK7) is expressed in red cells and plays a role in protection against oxidative damage. Blood Cells Mol. Dis. 2010, 45, 227-232.

108. Inberg, A.; Linial, M. Protection of pancreatic $\beta$-cells from various stress conditions is mediated by DJ-1. J. Biol. Chem. 2010, 285, 25686-25698.

109. Ng, C.J.; Hama, S.Y.; Bourquard, N.; Navab, M.; Reddy, S.T. Adenovirus mediated expression of human paraoxonase 2 protects against the development of atherosclerosis in apolipoprotein E-deficient mice. Mol. Genet. Metab. 2006, 89, 368-373.

110. Rajkovic, M.G.; Rumora, L.; Barisic, K. The paraoxonase 1, 2 and 3 in humans. Biochem. Med. 2011, 21, 122-130.

111. Ng, C.J.; Wadleigh, D.J.; Gangopadhyay, A.; Hama, S.; Grijalva, V.R.; Navab, M.; Fogelman, A.M.; Reddy, S.T. Paraoxonase-2 is a ubiquitously expressed protein with antioxidant properties and is capable of preventing cell-mediated oxidative modification of low density lipoprotein. J. Biol. Chem. 2001, 276, 44444-44449.

112. Fuhrman, B.; Khateeb, J.; Shiner, M.; Nitzan, O.; Karry, R.; Volkova, N.; Aviram, M. Urokinase plasminogen activator upregulates paraoxonase 2 expression in macrophages via an NADPH oxidase-dependent mechanism. Arterioscler. Thromb. Vasc. Biol. 2008, 28, 1361-1367.

113. Horke, S.; Witte, I.; Wilgenbus, P.; Krüger, M.; Strand, D.; Förstermann, U. Paraoxonase-2 reduces oxidative stress in vascular cells and decreases endoplasmic reticulum stress-induced caspase activation. Circulation 2007, 115, 2055-2064. 
114. Ng, C.J.; Bourquard, N.; Hama, S.; Shih, D.M.; Grijalva, V.; Navab, M.; Fogelman, A.M.; Reddy, S.T. Adenovirus-mediated expression of human paraoxonase 3 protects against the progression of atherosclerosis in apolipoprotein E-deficient mice. Arterioscler. Thromb. Vasc. Biol. 2007, 27, 1368-13674.

115. Shiner, M.; Fuhrman, B.; Aviram, M. Paraoxonase 2 (PON2) expression is upregulated via a reduced-nicotinamide-adenine-dinucleotide-phosphate (NADPH)-oxidase-dependent mechanism during monocytes differentiation into macrophages. Free Radic. Biol. Med. 2004, 37, 2052-2063.

116. Reddy, S.T.; Devarajan, A.; Bourquard, N.; Shih. D.; Fogelman, AM. Is it just paraoxonase 1 or are other members of the paraoxonase gene family implicated in atherosclerosis? Curr. Opin. Lipidol. 2008, 19, 405-408.

117. Larouche, A.; Berube, P.; Sarret, P.; Grignon, S. Subacute H2O2, but not poly(IC), upregulates dopamine D2 receptors in retinoic acid differentiated SH-SY5Y neuroblastoma. Synapse 2008, $62,70-73$.

118. Cachofeiro, V.; Goicochea, M.; de Vinuesa, S.G.; Oubiña, P.; Lahera, V.; Luño, J. Oxidative stress and inflammation, a link between chronic kidney disease and cardiovascular disease. Kidney Int. 2008, 74, S4-S9.

119. Bowie, A.; O'Neill, L.A. Oxidative stress and nuclear factor- $\kappa \mathrm{B}$ activation: a reassessment of the evidence in the light of recent discoveries. Biochem. Pharmacol. 2000, 59, 13-23.

120. Besser, M.J.; Ganor, Y.; Levite, M. Dopamine by itself activates either D2, D3 or D1/D5 dopaminergic receptors in normal human T-cells and triggers the selective secretion of either IL-10, TNFaor both. J. Neuroimmunol. 2005, 169, 161-171.

121. Laengle, U.W.; Markstein, R.; Pralet, D.; Seewald, W.; Roman, D. Effect of GLC756, a novel mixed dopamine D1 receptor antagonist and dopamine D2 receptor agonist, on TNF- $\alpha$ release in vitro from activated rat mast cells. Exp. Eye Res. 2006, 83, 1335-1339.

122. Zhang, Y.; Cuevas, S.; Asico L.D.; Escano, C.; Yang, Y.; Pascua, A.M.; Wang, X.; Jones, J.E.; Grandy, D.; Eisner, G.; et al. Deficient dopamine D2 receptor function causes renal inflammation independently of high blood pressure. PLoS One 2012, 7, e38745.

123. Laaksoa, A.; Pohjalainena, T.; Bergmanb, J.; Kajandera, J.; Haaparantac, M.; Solinb, O.; Syvalahtia, E.; Hietalad, J. The A1 allele of the human D2 dopamine receptor gene is associated with increased activity of striatal L-amino acid decarboxylase in healthy subjects. Pharmacogenet. Genomics 2005, 15, 387-391.

124. Ritchie, T.; Noble, E.P. Association of seven polymorphisms of the D2 dopamine receptor gene with brain receptor-binding characteristics. Neurochem. Res. 2003, 28, 73-82.

125. Rosmond, R.; Rankinen, T.; Chagnon, M.; Perusse, L.; Chagnon, Y.C.; Bouchard, C.; Bjorntorp, P. Polymorphism in exon 6 of the dopamine $\mathrm{D}_{2}$ receptor gene (DRD2) is associated with elevated blood pressure and personality disorders in men. J. Hum. Hypertens. 2001, 15, 553-558.

126. Thomas, G.N.; Tomlinson, B.; Critchley, J.A. Modulation of blood pressure and obesity with the dopamine D2 receptor gene Taq1 polymorphism. Hypertension 2000, 36, 177-182.

127. Carvey, P.M.; McGuire, S.O.; Ling, Z.D. Neuroprotective effects of D3 dopamine receptor agonists. Parkinsonism Relat. Disord. 2001, 7, 213-223. 
128. Zou, L.; Xu, J.; Jankovic, J.; He, Y.; Appel, S.H.; Le, W. Pramipexole inhibits lipid peroxidation and reduces injury in the substantia nigra induced by the dopaminergic neurotoxin 1-methyl-4-phenyl-1,2,3,6-tetrahydropyridine in C57BL/6 mice. Neurosci. Lett. 2000, 281, 167-170.

129. Le, W.D.; Jankovic, J.; Xie, W.; Appel, S.H. Antioxidant property of pramipexole independent of dopamine receptor activation in neuroprotection. J. Neural Transm. 2000, 107, 1165-1173.

130. Ferrari-Toninelli, G.; Maccarinelli, G.; Uberti, D.; Buerger, E.; Memo, M. Mitochondria-targeted antioxidant effects of $\mathrm{S}(-)$ and $\mathrm{R}(+)$ pramipexole. BMC Pharmacol. 2010, 10, 2.

131. Li, C.; Biswas, S.; Li, X.; Dutta, A.K.; Le, W. Novel D3 dopamine receptor-preferring agonist D-264: Evidence of neuroprotective property in Parkinson's disease animal models induced by 1-methyl-4-phenyl-1,2,3,6-tetrahydropyridine and lactacystin. J. Neurosci. Res. 2010, 88, 2513-2523.

132. Asico, L.D.; Ladines, C.; Fuchs, S.; Accili, D.; Carey, R.M.; Semeraro, C.; Pocchiari, F.; Felder, R.A.; Eisner, G.M.; Jose, P.A. Disruption of the dopamine D3 receptor gene produces renin-dependent hypertension. J. Clin. Invest. 1998, 102, 493-498.

133. Wang, X.; Escano, C.S.; Asico, L.; Jones, J.E.; Barte, A.; Lau, Y.S.; Jose, P.A.; Armando, I. Upregulation of renal D5 dopamine receptor ameliorates the hypertension in D3 dopamine receptor-deficient mice. Hypertension 2013, 62, 295-301.

134. Gribkoff, V.K.; Bozik, M.E. KNS-760704 [(6R)-4,5,6,7-tetrahydro-N6-propyl-2, 6-benzothiazole-diamine dihydrochloride monohydrate] for the treatment of amyotrophic lateral sclerosis. CNS Neurosci. Ther. 2008, 14, 215-226.

135. Okada, Y.; Sakai, H.; Kohiki, E.; Suga, E.; Yanagisawa, Y.; Tanaka, K.; Hadano, S.; Osuga, H.; Ikeda, J.E. A dopamine D4 receptor antagonist attenuates ischemia-induced neuronal cell damage via upregulation of neuronal apoptosis inhibitory protein. J. Cereb. Blood. Flow Metab. 2005, 25, 794-806.

136. Shimada, S.; Hirabayashi, M.; Ishige, K.; Kosuge, Y.; Kihara, T.; Ito, Y. Activation of dopamine D4 receptors is protective against hypoxia/reoxygenation-induced cell death in HT22 cells. J. Pharmacol. Sci. 2010, 114, 217-224.

137. Ishige, K.; Chen, Q.; Sagara, Y.; Schubert, D. The activation of dopamine D4 receptors inhibits oxidative stress-induced nerve cell death. J. Neurosci. 2001, 21, 6069-6076.

138. Bek, M.J.; Wang, X.; Asico, L.D.; Jones, J.E., Zheng, S.; Li, X.; Eisner, G.M.; Grandy, D.K.; Carey, R.M.; Soares-da-Silva, P.; et al. Angiotensin-II type 1 receptor-mediated hypertension in D4 dopamine receptor-deficient.mice. Hypertension 2006, 47, 288-295.

(C) 2013 by the authors; licensee MDPI, Basel, Switzerland. This article is an open access article distributed under the terms and conditions of the Creative Commons Attribution license (http://creativecommons.org/licenses/by/3.0/). 